\title{
The Application of New Media in the Field of Philanthropy
}

\author{
Jing Shang \\ Collage of Humanities and social science, Huazhong Agricultural University \\ jingshang19@yeah.net
}

\begin{abstract}
Philanthropy has long been an important means to maintain social stability and improve people's welfare, which is based on the wishes of donors to transform wealth between the rich and the poor. With the advent of new communication technology and the rise of mass media, "new media philanthropy" has become phenomenal. More and more people are using new media to post charitable messages. Many websites and social media are filled with messages asking for help. With the current situation of a large number of participants, a large scope of influence and a low threshold for participation, it is necessary to study new media charity to ensure its proper operation and healthy development. By carrying out document research on the use of new media in philanthropy, this research analyzes the main features of the "new media philanthropy" based on three different forms and amplifies how the new media works in the field of philanthropy. This research gives an insight into the significance and the dilemma of new media philanthropy. The results of this study indicate that new media philanthropy wins favor from people by lowering the barriers for both donors and beneficiaries, fully engaging the capacity of the viewer to empathize and providing tracked feedback. Simultaneously, there are some challenges that this new form of charity has to face, including harsh criticism, sustainable challenges. Besides, more exposure to mass media could lead to dignity damage of the recipient or cause vicarious traumatization to the donors.
\end{abstract}

Keywords: new media, philanthropy, philanthropic idea, social media

\section{INTRODUCTION}

With the development of new media, China has stepped into the era of social media. Guided by new media technology, a new trend has emerged in the charity industry - new media charity. Social media such as Weibo and WeChat have not only changed people's lives, but also their philanthropic ideas and behaviors. A total of 3.044 billion yuan was raised during the three-day online charity event for saving a cancered girl, setting a new record for public charity in China. New media charity is undoubtedly a direction for the future development of the charity industry.

There is no denying that the addition of new media has added momentum to traditional philanthropy. Whether in terms of influence, appeal or ability to raise funds, the addition of new media has given the traditional charity a qualitative leap forward. Thus, this paper uses the literature research method to explore the new forms and characteristics of new media charity in the current situation, starting from the characteristics of new media itself and combining with the features of the traditional charity industry. On this basis, the communication traits of new media and traditional charity are considered together, and the principles and mechanisms of new media in the field of charity are discussed. Finally, the positive and negative effects of new media charity in the current environment are examined.

In this era when everyone is a part of the media, the influence of new media is infinite. When such an "influence nuke" is combined with charity, which requires kindness, compassion, and willingness to help, people need to be more vigilant in screening the truth of information. Charity is a career that consumes goodwill. When people's goodwill is used to help the truly needy, it is not a drain on goodwill, but a diversion. But when people's goodwill is used for other purposes, the depleted trust is unrecoverable. The purpose of this article is to contribute to the clarification of the logic behind the operation of new media charity by peeking 
into the forms and characteristics presented by new media charity, so that such a powerful tool can be put on the right track and become an inexhaustible driving force for the prosperity of philosophy.

\section{LITERATURE REVIEW}

Among the existing studies, new media charity received not much attention, and relatively few studies have been conducted. From the perspective of traditional charity, Jing-Yi Gao argues that new media charity has characteristics such as interactive feedback, quick and timely, diverse forms and individual initiation [1]. Using the subject of charity initiation as a classification, Jing-Hua Gao divided new media charity into individual new media charity, organizational new media charity and platform new media charity, points out the advantages and disadvantages of new media charity, and argues that new media charity as a form of charity is irreversible[2]. Gregory D. Saxton1 and Chao Guo use descriptive research to explore the interconnection between non-profit organisations and online accountability [3]. Elaine Jeffreys and Jian $\mathrm{Xu}$ explain how the growth of the internet has allowed celebrities and their fans to be engaged in charitable matters [4]. Paul believes that Facebook and Twitter have become indispensable tools for charitable organisations, especially in times of disaster or crisis [5]. Non-profit organisations and voluntary organisations use social media such as Facebook to interact with the public to disseminate vital information and services in disaster situations.

\section{TWO FORMS OF NEW MEDIA PHILANTHROPY}

New media philanthropy refers to the philanthropic behaviour of charitable organisations, opinion leaders and people in need of help, who launch philanthropic activities to unite all classes of society, raising funds and spread philanthropic ideas through new media platforms; it also refers to the philanthropic behaviour that the public and enterprises who pay attention to, participate in through this medium. "New media philanthropy" is a charitable phenomenon, a specific charitable act, and a new form of philanthropy.

According to the role played by new media in charity activities, new media philanthropy can be divided into two forms: new media charity as a communication platform and new media charity as a fundraising platform. New media as a communication platform is the foundation, while new media as a fundraising platform is the economic continuation of its communication function.

\subsection{New media as a communication platform}

As a powerful platform, the central role of new media is to distribute charity information into a browsable information library. Thanks to the wide reach and precision of new media, charity information can be disseminated in a social, all-around, three-dimensional and interactive format. For example, in the case of the 2021 heavy rainfall in Henan, China, Sina Weibo launched relevant topics and dedicated search terms. On the one hand, this enabled direct communication between stranded people, official rescue teams and private rescue organisations, speeding up the speed and accuracy of search and rescue. On the other hand, the government authorities have been enabled to use big data to detect requests for help on dedicated terms, allowing them to adjust their overall control according to the actual situation in case of ground monitoring and other equipment failures. New media acts as a 'bridge' in this category, matching those in need with people and organisations who are willing to help, transferring material wealth and spiritual assistance from one side to the other.

There is a wide range of subjects who can initiate charitable activities. For example, Opinion leaders and social elites can use their personal influence to promote and spread the message of charity. Social organisations can also use social media to enhance their transparency, credibility and image. Moreover, Portals can set up specialized new media charity platforms to meet the needs of the public to seek help and participate in charity activities. For charitable organisations who wants to raise funds for charity projects and interact with donors and recipients while enhancing their own brand influence, the portal can be a useful tool. For personal users, those in need can use their own media to demonstrate their difficulties directly and honestly to the public, thereby gain attention to get through their struggles.

\subsection{New media philanthropy as a fundraising platform}

In this category, the promoter first uses new media as a communication platform to promote the charity message, attracting traffic and then, indirectly realizes funds through direct realization or indirect realization such as receiving a promotion. For example, "Cao Shimei, a blind mother", a blogger on the Chinese video site Bilibili, has made a significant difference to her life by posting videos of her daily life with her son with cerebral palsy. The account is not run by Cao Shimei herself, but by well-wishers in the same province as the video's protagonist, Cao Shimei. There are three main sources of donations and supplies: Firstly, viewers donate supplies directly through details provided by the blogger or by transferring money via card numbers. Secondly, the viewer likes or coins the video (available only within that video site, expressing the viewer's approval and appreciation of the video's content), and 
the video site realizes the coins and number of likes according to a certain percentage and distributes them to the blogger. Thirdly, bloggers use their accounts with a certain number of followers to work with brands, which earns promotion fees. New media charity as a fundraising platform is an economic realization using the communication function of new media, which essentially still plays the role of information dissemination.

\section{NEW MEDIA'S CHANGE OF CHARITY MODEL}

New media charity takes place on the Internet and therefore follows the basic logic of the Internet. This means content that inspires users' empathy and desire to participate will be provided, and convenient services for their engagement behaviour and feedback on real-time processes to satisfy their monitoring mentality will also be provided. Currently, the basic operating model of most new media charities is using storytelling to quickly inspire sympathy, applying visual information to emphasize the authenticity of the story, and to attract viewers to complete the donation on the charity platform, then to provide timely tracking feedback to maintain the user's idea of relief.

\subsection{New media as a dissemination channel for stories}

Storytelling is the process of telling a story with plots that connect what the viewer wants to know about a charity, thus increasing the impact and persuasiveness of the message[7]. In this process, it is not only necessary to emphasize the main charity message, such as "the eight-year-old leukemia patient". It is also necessary to explore the storytelling elements beyond the main message, such as "parents are disabled, but do not give up treatment" and "no relatives but help each other". New media charity no longer relies on tragic stories to appeal to the ethics of giving and helping, and it has become the main strategy and basic idea to explore the rare stories that the public enjoys.

\subsection{Strong visual impact of online video}

Visual impact means that, in the presentation of content, the weight of new media charity text gradually gives way to pictures and videos. Flowing thematic pictures with matching music, or tear-jerking short videos with text, all of them is a reflection of static and dynamic pictures and text. On this basis, to achieve a better communication effect, New Media Charity consciously highlights strong stimulating elements in the pictures or videos, such as dry and thin children, mutilated and injured people, to stimulate viewers' desire to click and encourage them to complete the act of donation.

\subsection{Benefits of faster feedback and public appreciations}

New Media Charity's messaging will continue after the donation is received. Follow-up coverage of charity projects is critical to sustaining user interest. New media philanthropy programs take advantage of the speed of information transmission to provide tracking feedback to each donor. For instance, the operator of "Blind Mother Cao Shimei" in the example above takes photos of each item and sends photos of the blind mother holding the donated goods to the donor to assure that the goods have actually reached the recipient. Tracking feedback is the key to keeping new media charities active and motivated by user donations. On this basis, some recipients even post their gratitude videos or messages publicly on new media platforms to convey their thankfulness to the general public. Faster feedback means higher satisfaction for the donor, while public appreciations satisfy the vanity of the donor to a certain extent. The combination of these two factors incentivizes donors to complete their donations more often through new media platforms.

\section{THE EFFECTS OF NEW MEDIA PHILANTHROPY}

\subsection{The Positive Effects}

First of all, new media charity lowers the threshold between the donating and receiving parties. Almost any kindness that is willing to give and any difficulty that is hard to be found can be spread by the subjects themselves through the Internet. In addition, the new media's convenience, low threshold, high-speed dissemination, a large amount of data and diversified content forms have broken the charitable discourse previously held by the government, charitable organizations and people in high social strata, making it possible for everyone to participate in charitable activities through the Internet. The equal communication mode allows the public to freely discuss and participate in charitable affairs on social media, and every like, retweet, comment, is a charitable act. New media charity is influencing people's concept of philanthropy, making the micro charity of a little love deeply popular. New media charity fully embodies the concept of charity for all.

\subsection{The Negative Effects}

New media charity also has many development dilemmas. At present, one of the problems of new media charity is that it is quite easy for the new media to be hurt by the harsh accusations of netizens in the primary development stage. While enjoying the convenience of new media, new media charity also has to bear the disadvantages it brings. The public's moral expectations 
of charity workers and institutions are getting higher and higher, and even the smallest mistakes may be infinitely magnified in online communication. A single bad charity event may trigger an uproar, forming rumors that smear the charity industry. The ecological environment of new media charity is even worse.

Secondly, the number of current new media charity projects continues to increase with multiple participating subjects and great influence. However, the corresponding regulatory bodies and systems have not yet been formed. In the era of information explosion, it is difficult to rely solely on information recipients to distinguish the truth from falsehoods. New media charity still needs corresponding regulatory bodies and regulatory platforms to filter information.

On top of that, since new media charity needs "trigger points" to attract clicks and donations, it tends to expose specific information such as photos and family situations of the recipients to the public since the beginning of its creation to gain sympathy. This is against the dignity of life pursued by modern charity.

Finally, due to the characteristics of new media such as big data precision pushing, the more often people give a helping hand to others, the easier it is for big data to mark them as active members of charity activities, thus receiving more information about help-seeking. Too much help information is likely to make charity donors suffer from vicarious traumatization, that is, after seeing too many cruel and destructive scenes, exceeding the limit of psychological tolerance, which indirectly leads to the psychological abnormal phenomenon. The chain-type push of new media charity provides the possibility for vicarious traumatization to occur.

\section{CONCLUSION}

This paper describes two forms of the role of new media in philanthropy. One is New media as a communication platform and the other is New media philanthropy as a fundraising platform. The paper further discusses that new media uses storytelling, visual impact, and efficient and public feedback to motivate donors to complete their donations. In addition, the paper identifies the positive impacts of new media philanthropy, including lowering the threshold for both parties, breaking the authority of discourse, and spreading the concept of philanthropy. However, new media charity also has certain problems, such as being vulnerable to harsh criticism that interferes with development, unformed regulatory institutions, violating the dignity of life, and easily causing vicarious traumatization.

This paper also has certain inadequacies. One is that the combination of new media and charity is relatively shallow and is analyzed from the perspective of donors and recipients. It has not considered the aspects of new media charity from the perspective of charities and new media platforms, nor has it looked at new media charity from the perspective of the whole charity industry. Secondly, the exploration of whether new media charity is ethical is not profound enough. New media charity can only follow the logic of the use of the Internet, using more dramatic information content to attract clicks and persuasion. Whether such persuasion is ethical and whether it constitutes secondary harm to the recipients is still worthy of further consideration.

New media philanthropy is a new phenomenon rooted in the communication characteristics of new media and has a catalytic effect on the future development of philanthropy. Future research can go beyond the perspective of both donors and recipients to explore new media philanthropy from a more macro and in-depth level. On the other hand, it is also important to continuously explore the motivation and the operation mechanism of participants in new media charity, so as to clear the obstacles for its institutionalization and standardization.

\section{REFERENCES}

[1] Jing-yi Gao." The difference between online public welfare and traditional public welfare and the trend of development." News World.09(2012):120-121. doi:CNKI:SUN:PXWS.0.2012-09-067.

[2] Jing-hua Gao(2018).The Significance and Dilemma of New Media Philanthropy. Journal of Hubei University(Philosophy and Social Science). 43.04(2018):154-160.doi:CNKI:SUN:HBDS.0.201 8-04-019.

[3] Saxton, G. D., \& Guo, C. (2009). Accountability Online: Understanding the Web-Based Accountability Practices of Nonprofit Organizations. Nonprofit and Voluntary Sector Quarterly, 40(2), 270-295. doi:10.1177/0899764009341086

[4] Jeffreys, E., \& Xu, J. (2017). Celebrity-inspired, Fan-driven: Doing Philanthropy through Social Media in Mainland China. Asian Studies Review, 41(2), 244-262. doi:10.1080/10357823.2017.1294

[5] Paul, M. J. (2001). Interactive Disaster Communication on the Internet: A Content Analysis of Sixty-Four Disaster Relief Home Pages. Journalism \& Mass Communication Quarterly, 78(4),739753. doi: $10.1177 / 107769900107800408$

[6] Kenneth Cukier - Viktor Mayer-Schönberger. BIG DATA Living, working and thinking big changes A REVOLUTION 